Mounir Abou-Madi MD FRCP(C),

Davy Trop MD FRCP(C), Lisc Morin MD FRCP(C), Andre Olivier MD PHD FRCs(C)

\title{
Anaesthetic considerations in percutaneous radiofrequency coagulation of the Gasserian ganglion
}

This. study determined the cardiovascular effects of percutaneous radiofrequency caagulation of the Gasserian ganglion, pefformed under neuroleptanalyesia and intermittent ultrashort-acting barbirurate anaesihesia. Twelve ASA physical staus class II patients were studied. Highty significant increases in mean heart rate and arterial blood pressure followed the insertion of the cannula electrode into the Gasserian ganglion $(p<0.001)$. In six randomly assigned patients severe tachycardia and hypertension also accompanied the progress of the thermal lesion ( $p<0.0001$ ). Three patients developed premature ventricular contractions, and two developed significant ST segment depression. Intruvenous nitroglycerin, used during current generation, successfully controlled the hypertensive response in the other six patients. In percutaneous thermocoagulation of the Gasserian gangiion the patient's co-operation is essential. In addition to providing suitabie operating conditions for both surgeons and parient, we should aiso be able to maintain normal and stable cardiovascular haemodyramics. Intravenous nitroglycerin used as an adjunct to light general anaesthesia safely maintained intraoperative normotension. $t \mathrm{t}$ is also

From the Departments of Anaesthesia and Neurosurgery, Montreal Neurological Hospital and Institute, and McGill University, Montreal, Quebec, Canada.

Address correspondence to: M. Abou-Madi, M.D., Department of Anaesthesia, Montreal Neurological Hospital, 3801 University Street - Rm 502, Montreal, Quebec, Canada H3A 2B4. suggested that patients with coronary artery disease be adequately monitored and protected during the procedure.

\section{Key words}

TRIGEMINAL NEURALGIA: radiofrequency coagulation; COMPLICATIONS: hypertension; ANAESTHETIC TECHNIQUES: neuroleptanalgesia; hypotension, nitroglycerin.

Percutaneous thermocoagulation of the Gasserian ganglion is a simple procedure recommended for patients who are too ill to undergo open surgery or in whom medical treatment has failed to control the symptoms of trigeminal neuralgia. The procedure is usually considered safe and is generally well tolerated ${ }^{1-4}$ The patients are semi-awake and their co-operation is maintained with neuroleptanalgesia and intermittent ultrashort-acting barbiturate anaesthesia. ${ }^{1,2}$ Although the technique is usually described as devoid of danger, even to the frail and elderly, cerebral and cardiovascular complications are now being reported more frequently., 2,3,5 Most studies simply neglect to report the common appearance of tachycardia, hypertension, and arrhythmias that accompany the procedure. ${ }^{1-7}$ The cardiovascular reactions are particularly hazardous for the hypertensive patient and those with advanced coronary or cerebral vascular insufficiency. The present study was therefore designed:

1. To demonstrate the effect of thermocoagulation of the Gasserian ganglion on the cardiovascular system;

2. To stress the importance of and need for 


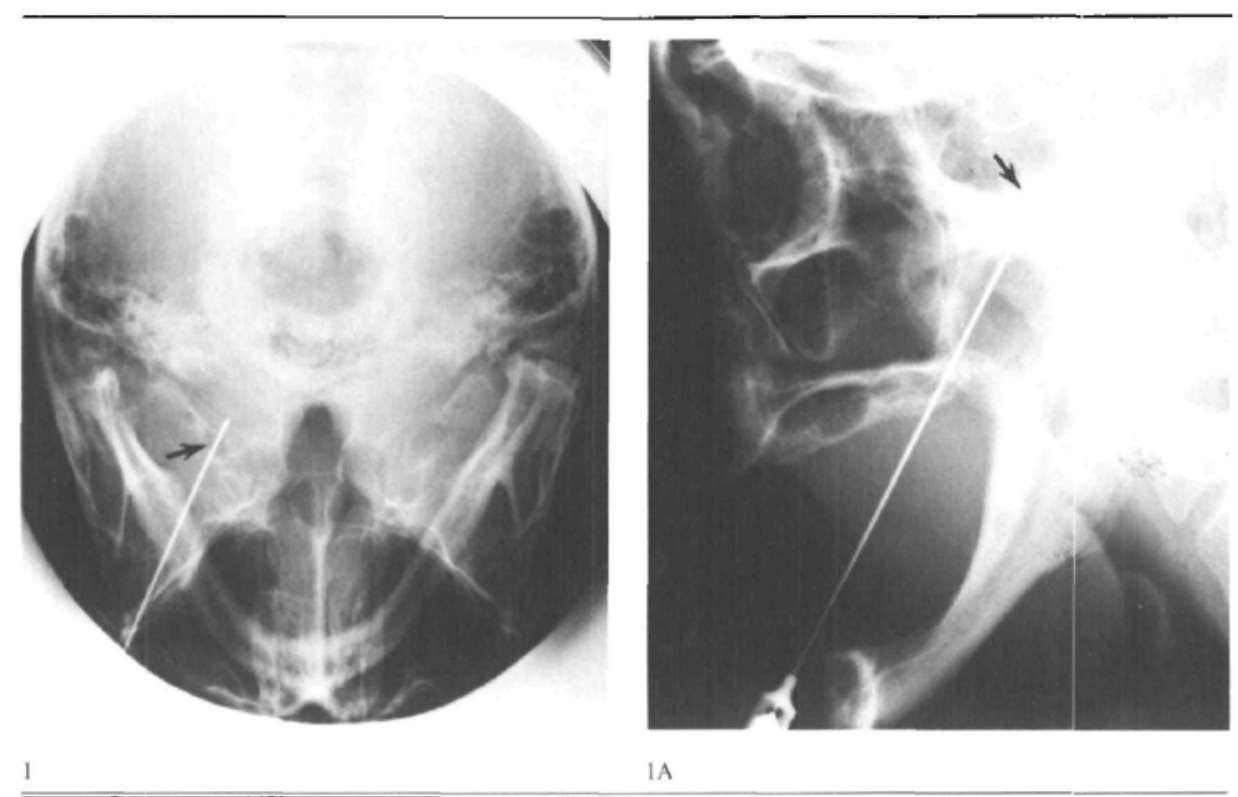

FIGURE 1-1A Basal and lateral views of skull to determine position of cannula electrode in foramen ovale.

continuous monitoring of these patients during the procedure;

3. To develop a technique to prevent cardiovascular reactions to thermocoagulation during the critical stages of the procedure.

\section{Methods}

The study protocol was approved by the Hospital Ethics Committee. Twclve patients (eight males and four females) of ASA physical status 11, who were scheduled to undergo thermocoagulation of the Gasserian ganglion consented to participate in the study. Their ages ranged from 61 to 71 years with a mean of $65.9 \pm 3.5$ (SD); their weights ranged from 51 to $74 \mathrm{Kg}$ with a mean of $64 \pm 6.9$. All patients were receiving carbamazepine, $800 \mathrm{mg}$ daily. The incidence of hypertension and ischaemic heart disease in the group was 66.6 per cent. Patients suffering from cerebral vascular insufficiency or severe atherosclerotic heart disease were excluded. No premedication was ordered. The thermocoagulation was done in the $x$-ray department. Under lidocaine topical analgesia, a peripheral vein was catheterized for infusion of fluids and administration of drugs and a 20-gauge teflon catheter was placed into a radial artery for measurement of systemic arterial blood pressure. Standard electro- cardiographic leads were attached and the pressure line was connected to a Bentlcy Tran:'ec Model 800 pressure transducer. Continuous electrocardiographic and systemic arterial blood pressure recordings were made on a Siemens Systen Sirecust 300 2-channel recorder. Neuroleptanalgesia was induced with intravenous fentanyl $1 \mu \mathrm{g} \cdot \mathrm{kg}^{-1}$ and droperidol $0.07 \mathrm{mg} \cdot \mathrm{kg}^{-1}$. The procedure was divided into three stages:

1. Electrode localisation,

2. Electrode stimulation,

3. Lesion production.

\section{Electrode localisation}

Under lidocaine topical analgesia, the cannula electrode was introduced percutaneously and a preliminary $x$-ray taken to determine its position in relation to the foramen ovale (Figure 1-1A). Control values of heart rate and arterial blood pressure were abtained. Methohexitone $0.6 \mathrm{mg} \cdot \mathrm{kg}^{-1}$ was injected intravenously to produce unconsciousness for the final insertion of the electrode into the Gasserian ganglion. Associated changes in heart rate and arterial blood pressure were recorded.

\section{Electrode stimulation}

The final placement of the electrode tip was 
TABLE I Heart rate and systemic arterial pressure

\begin{tabular}{|c|c|c|c|c|}
\hline \multirow[b]{2}{*}{ Stage } & \multicolumn{2}{|c|}{ Seart rate (beats/min) } & \multicolumn{2}{|c|}{ Systentic arterial pressure $(\mathrm{mm} / \mathrm{g}$ ) } \\
\hline & Pre & Post & Pre & Post \\
\hline $\begin{array}{c}\text { Localisation } \\
\qquad(n=12)\end{array}$ & $80.66 \pm 2.70$ & $108.08 \pm 2.57^{*}$ & $89.51 \pm 2.31$ & $143.42 \pm 3.75^{*}$ \\
\hline $\begin{array}{l}\text { Stimulation } \\
\qquad(n=12)\end{array}$ & $80.08 \pm 2.02$ & $86.12 \pm 1.96$ & $97.68=2.89$ & $101.13 \pm 2.02$ \\
\hline $\begin{array}{l}\text { Coagulation } \\
\text { Without NTG† } \\
(n=6)\end{array}$ & $82.00 \pm 5.31$ & $.20 .66 \pm 6.53^{*}$ & $94.38 \pm 4.08$ & $151.26 \pm 5.72^{*}$ \\
\hline $\begin{array}{l}\text { With NTG' } \\
(n=6)\end{array}$ & $96.00 \pm 2.37$ & $101.33 \pm 3.10$ & $77.62=3.10$ & $88.12 \pm 4.33$ \\
\hline
\end{tabular}

Mean \pm SEM

$* \mathrm{P} \leqslant 0.001$.

†NTG: Nitroglycerin.

determined by the response of the awake patient to electrode stimulation. A current of $0.2-0.3$ volts at $50-75$ cycles per second was used to elicit paraesthesias in the distribution of the involved sensory division. This was continued as long as necessary until the desired localisation and effect were obtained.

\section{Lesion production}

A radiofrequency lesion generator system, Model RFG-5, was used to produce the thermal lesion. At this stage patients were randomly assigned to two groups of six patients each. One group was given additional intravenous methohexitone $0.6 \mathrm{mg} \cdot \mathrm{kg}^{-1}$ to produce unconsciousness during the application of the lesion current $\left(60^{\circ} \mathrm{C}\right.$ for 120 seconds). The second group reccived, in addition to the methohexitone, an infusion of nitroglycerin, given two minutes before and during the progress of the thermal lesion. Nitroglycerin 0.03 per cent in five per cent dextrose in water was infused at variable rates to maintain the patients' systemic arterial blood pressures at levels below 140 torr systolic. The mean total dose of nitroglycerin was $8.51 \pm 2.44(\mathrm{SE}) \mathrm{mg}$. The mean infusion time was $4.00 \pm 0.53$ (SE) minutes.

Maximum changes in heart rate and systemic arterial blood pressure were recorded during the progress of the thermal lesion in both groups. Careful sensory testing was conducted when the patients were fully awake. Patients were returned to their rooms after their vital signs were completely stable. Statistical analysis of the results was carried out using Student's test and analysis of variance. $P$ values of less than 0.05 were accepted as significant.

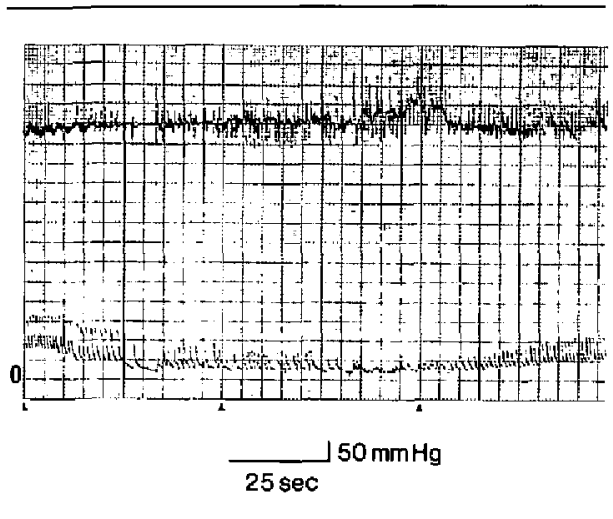

FIGURE 2 Sevęre dysrhythimia and curdiac asystole ( 115 seconds) following introduction of cannula electrode in foramen ovale. Patient tesponded to external cardiac massage and atropine $1.6 \mathrm{mg}$ IV,

\section{Results}

Data are presented as the mean \pm the standard error of the mean (S.E.M.)

The two groups were comparable in age, weight, and incidence of atherosclerotic heart disease. In all patients a significant increase in heart rate and mean systemic arterial blood pressure accompanied the introduction of the cannula electrade into the Gasserian ganglion ( $p<0.001$ ) (Table I). One patient developed severe bradycardia and sinus arrest, but responded to intravenous atropine $1.6 \mathrm{mg}$ (Figure 2). His recovery was uneventful and he was assigned one week later to the nitroglycerin group 


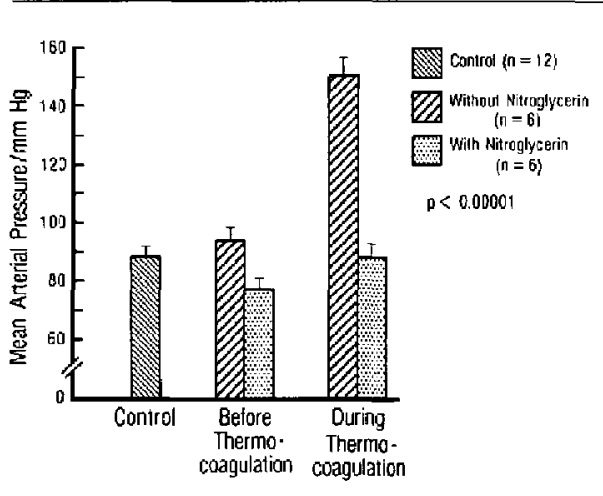

FIGURE 3 Mean systemic arterial blood pressure \pm SE, with and without nitroglycerin, before and during thermocoagulation of the Gasserian ganglion.

of patients. No significant changes in hear rate and arterial blood pressure accompanied the electric stimulation of the Gasserian ganglion. Table I and Figures 3, 4, and 5 show the protective effect of the nitroglycerin in controlling the hypertensive response to thermocoagulation in the six treated patients. All patients remained normotensive. In the control group severe cardiovascular reactions accompanied the progress of the thermal lesion. All six patients became severely hypertensive $(\mathrm{p}<0.0001)$, three patients with pre-existing atherosclerotic heart disease developed premature ventricular contractions, and two developed significant ST segment depression. All observed changes disappeared shortly after cessation of the thermal current.

\section{Discussion}

Trigeminal neuralgia is characterized by extremely intense paroxysms of pain confined to one or more divisions of the trigeminal nerve.

Three types of acute facial pain are described:

1. Idiopathic "essential" trigeminal neuralgia (tic douloureux) is a disease that rarely clears spontaneously, and causes great suffering, mainly among the elderly. It occurs more commonly in males and more frequently on the right side of the face. ${ }^{8}$ It responds fairly well to carbamazepine and diphenylhydantoin therapy. ${ }^{9}$ Pharmacological treatment, however, rarely controls the pain without elevated drug concentrations that can cause unpleasant side effects. Furthermore, any patient needing drug

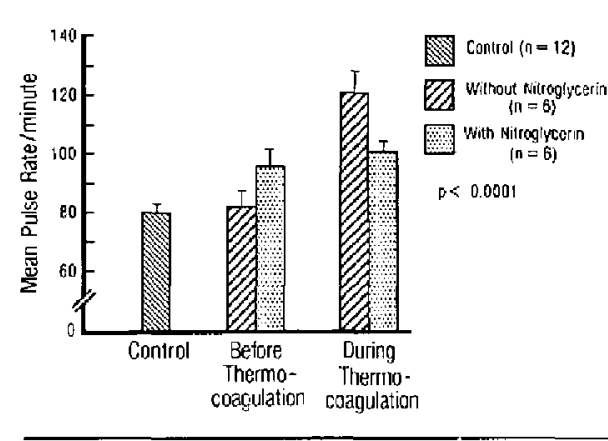

FIGURF 4 Mean pulse rate (beats/minute) $\pm S E$, with and without nitroglycerin, before and during thermocoagulation of the Gasserian ganglion.

therapy will require it, on and off, for the rest of his life. Patients who are intolerant or become refractory to medical treatment are managed surgically.

2. Symptomatic trigeminal neuralgia, post-traumatic or post-herpetic, can also accompany disseminated multiple sclerosis, carcinoma, Paget's discasc, aneurysm, basilar meningitis, and sellar tumours. Surgery is indicated to reduce pain and discomfort, and is effective in most cases.?

3. Atypical trigeminal pain comnonly follows chronic dental and sinus problems, and/or multiple surgical interventions. Most patients clo not respond to treatment.?

A detailed description of the miny operative procedures available for the treatment of trigeminal neuralgia is beyond the scope of this paper. Briefly, however, they include: (1) Peripheral. nerve blocks

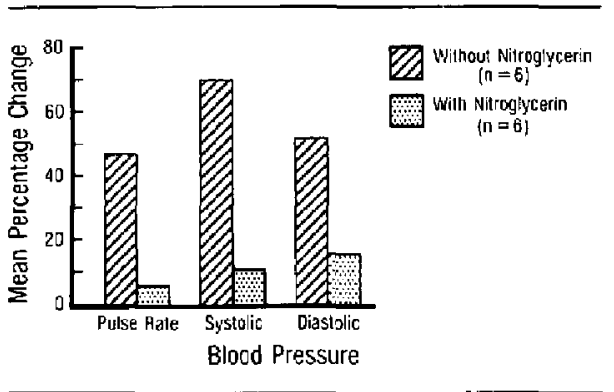

FIGURE 5 Effect of IV nitroglycerin on mean percentage change in pulse rate and arterial blood pressure during thernocoagulation of the Gasserian ganglion. 
and avulsions, usually done to control temporarily chronic trigeminal neuralgia and to test the patient for sensory deprivation; (2) Major craniotomies and selective intracranial root sections; ${ }^{\prime}$ (3) Janetta microvascular decompressive operation; ${ }^{10.11}$ (4) Controlled percutaneous radiofrequency lesion; ${ }^{1,2}$ (5) Percutaneous glycerol injections into the trigeminal cistern. ${ }^{12,13}$

The old technique of percutaneous instillation of liquid agents (alcohol, ${ }^{14,15}$ sulphonamide, ${ }^{16}$ boiling water, ${ }^{17}$ phenol ${ }^{18}$ ) and heat ${ }^{19,20}$ into the Gasserian ganglion resulted in many complications and uncontrolled spread of neural destruction.

Sweet et al. in America, ${ }^{2}$ and Schurman et al. in Germany ${ }^{1}$ repopularized the percutaneous approach, with three modifications. (1) They used radiofrequency generators to destroy selectively the small and less myelinated pain fibres, ${ }^{21,22}$ (2) they graded heat production to spare the touch fibres, ${ }^{22}$ and (3) they used neuroleptanalgesics and ultrashort-acting barbiturates to produce brief unconsciousness.

Their technique, which eliminated deficits outside the trigeminal nerve, made this method the operation of choice for trigeminal neuralgia.

Because of its minimal operative risk and low rate of complication, neither age nor debility is considered a contraindication to the procedure. Unconsciousness is induced with methohexithone each time a thermal current is delivered. No data, however, are available in the literature on monitoring of these patients. Our study has clearly demonstrated that, even under narcosis, alarming cardiovascular reactions accompany both the puncture and the coagulation of the Gasserian ganglion. The way these patients are rendered analgesic and unconscious is precarious and often hazardous. It affords no protection against reflex autonomic nervous system stimulation, a matter of concern in patients with coronary artery disease or associated cerebral vascular insufficiency.

Puncture of the unanaesthetized Gasserian ganglion produces very intense pain. Nociceptive impulses associated with the sensory nucleus of the fifth cranial nerve pass and stimulate both spinal anterolateral horn cells and brainstem neurones involved in the control of ventilation, circulation, and hypothalamic function. The reflex response might consist of either an abnormal vagal reflex, consisting of bradycardia, arterial hypotension and atrio-ventricular block or sympathetic hyperactivity, with increase in cardiac output, work, and myocardial oxygen consumption. ${ }^{23}$ Animal studies also suggest that segmentally induced sympathetic stimulation produces reflex coronary vasoconstriction that will further impair the delivery of oxygen to the myocardium. ${ }^{24}$ Moreover, sympathetic hyperactivity exacerbates the four main factors affecting the delicate balance between myocardial oxygen supply and myocardial oxygen demand in patients with coronary artery disease; these factors are hypertension, tachycardia, increased heart volume and increased contractility. In their study on myocardial ischaemia during anaesthesia, Roy et al ${ }^{25}$ determined the relationship between increases in blood pressure and heart rate and episodes of ST-segment depression. They showed a 38 per cent incidence of ST-segment depression intraoperatively in patients with known coronary antery disease. The increased rate-pressure product occurred most often about the time of intubation and correlated well with myocardial ischaemia and ST-segment depression. ${ }^{26}$

Intraoperatively the deleterious effects of tachycardia and hypertension can usually be prevented by an adequate level of general anaesthesia. If this is not possible because of surgical considerations, as is the case in patients undergoing percutaneous thermocoagulation of the Gasserian ganglion, then every effort should be made to block the hypertensive response to surgical stimulation, decrease the afterload, reduce myocardial oxygen demand, and prevene ischaemia. Vasodilators and $\beta$-adrenergic blocking drugs have recently been used in the perioperative period for the treatment of hypertension not adequately controlled by other measures. Systemic vasodilatation can be produced by many drugs with varied mechanisms and with different sites of action. ${ }^{27}$ Nitroglycerin might be the preferred vasodilator in patients with coronary artery disease because it: (1) modifies the relationship between myocardial oxygen demand and supply; (2) reduces left ventricular wall tension, a primary determinant of myocardial oxygen consumption; ${ }^{28,29}$ (3) diminishes resistance to collateral flow in patients with multi-vessel coronary involvement and redistributes coronary blood flow to subendocardial ischaemic areas; ${ }^{30}$ (4) causes primary venous dilatation and therefore has a minimal intracoronary steal effect; ${ }^{31}(5)$ and finally, causes minimal increases in heart rate and has no known toxicity. To avoid inconsistency in response because of adsorption of 
nitroglycerin to polyvinylchloride, the use of a special polyethylene intravenous administration set has been recommended. ${ }^{32}$

Intravenous propranolol, a $\beta$-adrenergic blocking agent, has also been extensively used to control serious intraoperative tachyarrhythmias, hypertension, and myocardial ischaemia. ${ }^{33}$ Its use, however, might facilitate vagal cardioinhibition and cause excessive cardiac depression. If intense peripheral $\alpha$-adrenergic receptor stimulation cxists, intravenous propranolol can lead to acute cardiac decompensation. With so much attention to the dangers of hypertension, it is important to emphasize that hypotension also must not be ignored. Prolonged intraoperative hypotension is a risk associated with an increased rate of reinfarction in patients who previously had a myocardial infarction. Hypotension is usually defined as a 30 per cent drop in systolic arterial pressure from preoperative levels for ten minutes or more, one or more times during the operation. ${ }^{34,35}$ Most cardiac anaesthetists agree, however, that patients who have coronary artery disease have impaired tolerance to any added intraoperative stress and suggest the use of moderate hypotension (10-20 per cent) to preserve the patient's myocardial oxygen balance. ${ }^{36,37}$

In addition to providing suitable operating conditions for both surgeon and patient, one must also be able to maintain adequate coronary perfusion and safely reduce myocardial oxygen requirements.

In anaesthesia for thermocoagulation of the Gasserian ganglion, many combinations of drugs have been used to ensure an anaesthetic depth from which the patient can easily be awakened. Our study has shown that a technique of light anaesthesia is frequently associated with hypertension, tachycardia, and various amhythmias. It can also cause marked cardiovascular stress for any patient with known or suspected coronary artery disease.

Because of these considerations and to maintain stable cardiovascular haemodynamics we have used intravenous nitroglycerin intraoperatively as an adjunct to light anaesthesia. The technique proved to be safe and efficient; it maintained intraoperative normotension and was devoid of complications or side effects. These patients should have continuous recording of heart rate and arterial blood pressure, and should be monitored using an electrocardiographic lead sensitive to myocardial ischaemia.

\section{Acknowledgement}

The authors gratefully thank Dr. D.R. Bevan and Dr. D. Archer for the statistical analysis, Dr. V. Lees for editing the manuscript, and Miss N. Durepos for her clerical assistance.

\section{References}

1 Schürmann $K$, Butz $M$, Brock $M$. Temporal retrogasserian resection of trigeminal root versus controlled clective percutaneous electrocoagulation of the ganglion of Gasser in the trcatment of trigeminal neuralgia. Acta Neurochir 1972; 26: 33-53

2 Sweet WH, Wepsic JG. Controlled thermocoagulation of trigeminal ganglion and rootlets for differential destruction of pain fibers. Part 1: Trigeminal neuralgia. J Neurosurg 1974; 40: 143-56.

3 Nugen $G B$, Berry $B$. Trigeminal neuralgia treated by differential percutaneous radiofrequency coagulation of the Gasserian ganglion. J Neurosurg 1974; 40: $517-23$.

4 Turnbull IM. Percutaneous rhizotomy for trigeminal neuralgia. Surg Neurol 1974; 2: 385-9.

5 Thiry S, Hotermans JM. Traitement de la névralgie cssentielle du trijumeau par stérćotaxis: et électrocoagulation partielle sélective du ganglion de Gasser. Neuro-chirurgie 1974; 20: 55-60.

6 Onofrio BM. Radiofrequency percutaneous Gasserian ganglion lesions. Results in 140 patients with trigeminal neuralgia. J Neurosurg 1975; 42: 132-9.

7 Siegfried $J .500$ percutaneous thermocoagulations of the Gasserian ganglion for trigeminal pain. Surg Neurol 1977; 8: 126-31.

8 Rothman KJ, Wepsic JG. Side of facial pain in trigeminal neuralgia. J Neurosurg 1974; 40: 514-6.

9 Rasmussen P. Ruischede J. Facial pain treated with carbamazepine (Tegretol). Acta Neurol Scand 1970; 46: 385-408.

10 Janetta $P$. Microsurgical approach to the trigeminal nerve for tic douloureux. Progress in neurological surgery, vol 7. Basel, Karger, 1976; pp. 180-200.

11 Dandy $W E$. Concerning the cause of trigeminal neuralgia. Am J Surg 1934; 24: 447-5:5

12 Håkanson $S$. Treatment of trigemiral neuralgia by injection of glycerol into the trigeminal cistem. Neurosurgery $1981 ; 9: 638-46$.

13 Sweet WH, Poletti CE, Macon JB. Treatment of trigeminal neurajgia and other facial pains by retrogas serian glycerol. Neurosurgery $1981 ; 9$ : 647-53.

14 Harris $W$. Alcohol injection of the Gasserian ganglion for trigeminal neuralgia. Lancet $1912 ; 1 \div 218-21$ 
15 Thurel $R$. Alcoolisation du ganglion de Gasser et diffusion de l'aicool aux formations nerveuses $\mathrm{du}$ voisinage. Rev Neurol 1961; 104: 78-9.

16. Jelasic $F$. Injektionsbehandlung der trigcrinusneuralgic mit sulfonamidlosungen. Med Klinik 1952; 47: 1537.

17 Jaeger $R$. The results of injccting hot water into the Gasserian ganglion for the relief of tic douloureux. J Neurosurg 1959; 16: 656-63.

18 Jefferson $A$. Trigeminal root and ganglion injections using phenol in glycerine for the relief of trigeminal neuralgia. J Neurol Neurosurg Psychiatr 1963; 26: 345-52.

19 Kirsehner $M$. Elektro-congulation des ganglion gasseri. Zentralbl Chir 1932; 47: 2841-3.

20 Kirschner $M$. Die behandlung der trigeminusneuralgie (nach erfahrungen an 1113 kraken). Munchen Med Wschr 1942; 89: 235-9.

21 Letcher FS, Goldring S. The effect of rudiofrequency current and heat on peripheral nerve action potential in the cat. $J$ Neurosurg 1968; 29: 42-7.

22 Frigyesi $T L$, Siegfried J, Broggi $G$. The selective vulnerability of evoked potentials in the trigeminal sensory root to graded thermocoagulation. Experimental Neurology 1975; 49: 11-21.

23 Zanchetti $A$, Malliani $A$. Ncural and psychological factors in coronary disease. Acta Cardiologica (supp.) 1974; 20 : 69-89.

24 Feigl EO. Control of myocardial oxygen tension by sympathetic coronary vasoconstriction in the dog. Circ Res 1975; 37: 88-95.

25 Roy WL, Edelist G, Gilbert B. Myocardial ischemia during non-cardiac surgical procedures in patients with coronary-artery diseasc. Anesthesiology 1979; 51: 393-7.

26 Rifkin DR, Hood WB, Jr. Bayesian analysis of electrocardiographic exercise stress testing. N Engl J Med 1977; 297: 681-6.

27 Gerson $J I$, Allen FB, Seltzer $J L$. Arterial and venous dilatation by nitroprusside and nitroglycerin - Is there a difference? Anesth Analg 1982; 61: 256-60.

$28 \mathrm{Katz} \mathrm{AL}$. Myocardial protection in the coronary care unit and the operating room. ASA refresher courses in anaesthesiology. Herskey $S G, J \mathrm{~B}$ Lippincolt $\mathrm{Co}$. Philadelphia, vol. 10, 1982; pp 13!-42.

29 Sethna DH, Moffit EA, Bussell JA et al. Intravenous nitroglycerin and myocardial metabolism during anesthesia in patients undergoing myocardial revascularization. Anesth Analy 1982; 61: 828-32.
30 Goldstein RE, Stinson $E B$, Scherec $J L$ et al. Intraoperative coronary collateral function in patients with coronary occlusive disease. Circulation 1974; 49: 298-308.

31 Mann T, Cohn PF. Holman BL et al. Effect of nitroprusside on regional myocardial blood flow in coronary artery disease: Results in 25 patients and comparison with nitroglycerin. Circulation 1978; 57 : 732-7.

32 Cote $D D$, Torchia MT. Nitroglycerin adsorption to polyvinylchloride seriously interferes with its clinical use. Anesth Analg 1982; 61: 541-3.

33 Safwat AM, Reitan JA, Misle GR et al. Use of propranolol to control rate-pressure product during cardiac anesthesia. Anesth Analg 1981; 60: 732-5.

34 Steen $P A$, Tinker $J H$, Tarhan S. Myocardial reinfarction after anesthesia and surgery. JAMA 1978; 239: 2566.

35 Mauney FM Jr, Ebert PA, Sabiston DC Jr. Postoperative myocardial infarction: a study of predisposing factors, diagnosis, and mortality in a high risk group of surgical patients. Ann Surg 1970; 172: 497-503.

36 Lowentstein $E$. Anesthetic considerations in coronaryartery disease. ASA refresher courses in anesthesiology. Hershey SG, JB Lippincott Co., Philadelphia, vol 4, 176; pp 51-62.

37 Attia RR, Murphy JD. Snider MT et al. Myocardial ischemia due to infrarenal aortic cross-clamping during aortic surgery in patients with severe coronary artery disease. Circulation 1976; 53: 961-5. 


\section{Résumé}

La thermocoagulation du ganglion de Gasser par une approche percutanée est faite avec l'appoint d'une technique de neuroleptanalgésie ef ['utilisation de barbituriques a action ultra-courte. Les effets de la chirurgie et de l'anesthésie sur les paramètres cardiovasculaires ont été relevés chez douze patients classés en catẹgorie ASA II. Une augmentation marquee de la frequence cardiaque et de la pression artérielle systémique a été observée an moment de l'insertion de l'électrode dans le ganglion de Gasser $(p<0.001)$. Six patients ont prêsentè une. achycordie et une hypertension sévère au cours de la coagulation $(p<0.0001)$; chez trois patients des extrasystoles ventriculaires sant apparues, tandis quion notait une dépression significative du segment ST chez deux patients. La nitroglycérine par voie intraveineuse a été utilisée avec succès chez six autres pariens; cette drague a permis de contrôler la réponse hypertensive lors de la coagulation. La coopération et la participation du patient sont indispensables au succès de la procédure chirurgicale et une technique anesthésique de très courte durée assure les meilleures conditions de travail au chirurgien. Par ailleurs, comme beaucoup de ces parients sont agés et hypothéqués, il faut veiller à ne pas aggresser la fonction hémodynamique et à maintenir tension artérielle et fréquence cardiaque dans des limires normales. La nitroglycérine intraveineuse combinée à une anesthésie légère protège le patient en empêchant les fucluations cardiovasculaires marquées. Quelle que soit la technique utilisée, il est essentiel de surveiller de très press les patients lors de certe procédure chirurgicale. 